Demirkesen, S, Wachter, N., Oprach, S., Haghsheno, S. (2019). "Identifying Barriers in Lean Implementation in the Construction Industry" In: Proc. 27 th Annual Conference of the International. Group for Lean Construction (IGLC), Pasquire C. and Hamzeh F.R. (ed.), Dublin, Ireland, pp. 157-168 DOI: https://doi.org/10.24928/2019/0151. Available at: 〈www.iglc.net>.

\title{
IDENTIFYING BARRIERS IN LEAN IMPLEMENTATION IN THE CONSTRUCTION INDUSTRY
}

\author{
Sevilay Demirkesen ${ }^{1}$, Nadia Wachter ${ }^{2}$, Svenja Oprach ${ }^{3}$, and Shervin Haghsheno ${ }^{4}$
}

\begin{abstract}
With the rising attention on the topic of Lean construction and its benefits, more and more companies aim to implement the Lean philosophy in their culture. Together with changing the companies' culture multiple challenges occur. Hence, it is of utmost importance to identify factors, which lead to poor management in Lean construction activities. Therefore, this paper intends to identify and categorize barriers leading to poor implementation of the Lean philosophy. In this respect, a set of barrier groups comprising a total of twenty-seven components were identified. A questionnaire was designed and administered to Lean construction professionals in order to rank the importance level of the selected barriers. The paper proposes that lack of 'top management support', 'misperception about Lean practices', 'lack of information sharing and integrated change control' are the top three barriers for Lean implementation. The findings of the study indicate that Lean implementation might be conducted with higher efficiency and productivity by removing the barriers for implementation. This study might guide Lean professionals to align their strategies with Lean practices by knowing and recognizing the main barriers.
\end{abstract}

\section{KEYWORDS}

Lean construction, culture, collaboration, continuous improvement, barriers.

\section{INTRODUCTION}

Construction is a risky endeavor and it requires the application of well-set practices. Bringing a new insight to construction industry, Lean construction appears as a new branch of construction management (Ballard and Howell, 2004). Due to a lack of experience, Lean construction projects are sometimes troublesome and challenging for contractors.

Assistant Professor, Dept. of Civil Eng., Gebze Technical University, Kocaeli, Turkey. Phone +90 5340540364, demirkesen@gtu.edu.tr.

2 Research Fellow. Karlsruhe Institute of Technology (KIT), Institute of Technology and Management in Construction, Gotthard-Franz-Str. 3 (Am Fasanengarten), Bldg. 50.31, D-76131 Karlsruhe, Germany. Phone +49 (0) 721608 45476, nadia.wachter@kit.edu.

3 Research Fellow. Karlsruhe Institute of Technology (KIT), Institute of Technology and Management in Construction, Gotthard-Franz-Str. 3 (Am Fasanengarten), Bldg. 50.31, D-76131 Karlsruhe, Germany. Phone +49 (0) 721608 45476, svenja.oprach@ kit.edu.

4 Professor. Karlsruhe Institute of Technology (KIT), Institute of Technology and Management in Construction, Gotthard-Franz-Str. 3 (Am Fasanengarten), Bldg. 50.31, D-76131 Karlsruhe, Germany. Phone +49 (0)721 608 42646, shervin.haghsheno@ kit.edu. 
Meadows (2011) indicates that processes in the construction industry are more wasteful than processes of any other industry. Hence, eliminating non-value adding activities is of utmost importance in the construction industry to stay competitive. The Construction Industry Institute (CII) reports that according to studies $57 \%$ of the construction work results in waste (Aziz and Hafez, 2013; Lean Construction Institute, 2004). This necessitates the effective implementation of strategies to minimize waste and promote competitiveness (Porter, 1995).

Introducing Lean thinking to the construction industry is not only beneficiary for practitioners but also for customers regarding the transparency and stability of the project. Koskela (1992) considers Lean principles in the construction context and proposes methods to manage construction projects accordingly (Koskela, 1992). Nevertheless, it is still troublesome to accurately transfer Lean principles to construction projects and achieve an efficient implementation by construction professionals. Moreover, most contractors are reluctant to apply Lean principles since the implementation is perceived as expensive and time consuming (Almanei et al. 2017; Okere 2017). Therefore, Lean implementation is sometimes evaluated as a disadvantage for short term projects despite its advantages in long-term. Hence, it might become difficult for contactors to recognize the benefits of Lean practices.

To refute the idea that Lean construction principles are not beneficiary or only have limited benefits for construction practitioners, a better understanding of Lean practices and a clear definition of Lean implementation barriers is required. Thus, this study aims to identify main barriers preventing construction practitioners from the benefits of Lean practices. Additionally, the positive influence of an effective implementation of Lean practices is outlined. In this respect, seven factor groups were identified comprising twentyseven components. The factor groups identified are namely the following: political, economical, managerial, workforce, culture, communication, and technical. The study also presents the results of a questionnaire administered to Lean professionals in the USA in terms of ranking the identified barriers based on the order of importance.

\section{RESEARCH METHOD}

In the first step an in-depth literature review was conducted in order to identify barriers for Lean implementation in construction. In the second step, an online survey was designed and administered to the members of the Lean Construction Institute (LCI) (https://www.leanconstruction.org/membership/members-sponsors/\#Corporate\%20

Members). The members were selected considering their level of expertise in practicing Lean. A comprehensive list was generated after careful investigation of members' expertise and experience in Lean construction. Then, the survey was delivered online to come up with a better response rate. The survey consisted of two sections: (1) general information about the respondent, company, and project and (2) the barriers associated with Lean implementation. After a brief overview of Lean Implementation in construction, findings from literature review and the survey are presented in the following. 


\section{LEAN IMPLEMENTATION IN CONSTRUCTION PROJECTS}

The construction industry is a dynamic and fragmented industry, which requires the adoption of various tools and techniques for the effective management of construction projects. In this respect, Lean techniques are useful in terms of promoting efficiency in the industry and increasing productivity rates (Sundar et al. 2014). When the Toyota company developed its production system (TPS) in the 1950s, the company increased its profits every year from 1950 to 2008 until the global recession and the oil price spike (Liker and Convis, 2012). According to the two pillars of the TPS, not only processes but also the people's mindset is fundamental for a successful development. Lean production was then offered as a term by Krafcik, a member of the team of the International Motor Vehicle Programme at the Massachusetts Institute of Technology (MIT) in 1988 (Krafcik, 1988). Womack et al. (1990) further studied this concept in their book "The Machine That Changed the World".

Koskela (1992), one of the Lean pioneers, brought up Lean principles for the fact that these principles aim to maximize value for customers while minimizing waste (Koskela 1992, Sarhan and Fox 2013). Womack and Jones (1996) further mentioned the five principles of Lean production namely specify value, identify the value stream, make the remaining value-creating flow continuously, allow customers to pull, and reach perfection for a continuous improvement process. This theoretical foundation is called 'Lean Thinking' and it helps differentiating production activities in value adding and non-value adding activities (Terry and Smith 2011; Sarhan and Fox 2013). In this respect, Lean production and construction introduce eight types of waste, namely the "transportation, inventory, motion, waiting, over-production, over-processing, defects, and skills misuse" respectively (Terry and Smith 2011; Sarhan and Fox 2013).

The use of Lean thinking in construction projects has already proven its benefits. These benefits include but are not limited to productivity improvement, increased reliability, quality improvement, increased customer satisfaction, realistic schedules and reduced durations, less waste, and design as well as safety improvements (Mossman 2009). However, industry practitioners still find Lean implementation challenging due to lack of information related to Lean principles. This proves that there are certain barriers in adopting Lean concepts and successfully apply them (Mossman 2009, Sarhan and Fox 2013). Several other studies also pointed out that Lean implementation is challenging for the construction industry (Ayarkwa et al. 2012, Wandahl 2014). Therefore, this paper aims to reveal barriers of Lean construction implementation in order to provide a set of core barriers that industry practitioners should investigate for getting the maximum benefit from applying Lean practices.

\section{BARRIERS OF LEAN IMPLEMENTATION}

Several studies identified a set of barriers in Lean implementation generally focusing on a specific region. For example, Devaki and Jayanthi (2014) studied the barriers of Lean implementation in the Indian construction industry and identified 11 barriers, some of which are "lack of exposure regarding the need for Lean construction", "uncertainty in the supply chain", and "the tendency to apply traditional management methods". Similarly, 
Ayarkwa et al. (2012) studied the barriers existing in the Ghanaian construction industry and listed "fragmented nature of the industry", "extensive use of subcontractors", "lack of long-term relationship with subcontractors" as the top ranked barriers. Sarhan and Fox (2013) identified "fragmentation and subcontracting", "procurement and contracts", and "lack of adequate Lean awareness and understanding" as the key barriers in their study.

In this in-depth literature review, barriers of Lean implementation were identified and a total of thirty-two barriers were developed. To come up with valid barriers, several pilot studies were conducted. In these pilot studies, the barriers were discussed with three university professors and four industry practitioners and some of the barriers were revised to best reflect their corresponding factors. After careful consideration of barriers, some of the barriers were either synthesized or removed where necessary. For example, lack of information sharing and integrated change control were mostly listed as two separate barriers in Okere's (2017) study. However, these two barriers are strongly interrelated with managing uncertainties and changes. Hence, the study evaluated these two as one barrier. A similar approach was adopted for the remaining barriers. The barriers were carefully determined considering most up-to-date data in construction projects. Moreover, barriers were grouped with a systematic approach called PEST. With the PEST analysis, influencing factors on an organization were systematically structured. PEST is an acronym for 'political', 'economical', 'socio-cultural' and 'technological' (Steinmann and Schreyögg 2006).

Based on this model and the literature study, twenty-seven barriers were identified for Lean implementation. The factor groups and the respective barriers are shown in Figure 1. These barriers are identified as the key barriers causing challenges in Lean implementation in construction projects. As seen in Figure 1 most of the detected barriers can be found in the socio-cultural area consisting of the managerial, cultural, communication and workforce barriers. The definition of each barrier along with the evidence from literature is presented in the following.

\section{Political Barriers}

Stringent requirements and approvals: Information flow and procedural documents might take time and lead to deficiencies in Lean processes. This makes governmental organizations hesitant about the benefits and applications of Lean practices. Hence, stringent requirements and approvals might be a burden for governmental organizations (Shang and Pheng 2014, Almanei et al. 2017).

Lack of knowledge in Lean: The Lean philosophy is still not yet entirely understood by most of governmental authorities, so benefits are not conceived in turn. This might negatively affect investment decisions in construction projects, where Lean practices are planned to be applied (Sarhan and Fox 2013). 


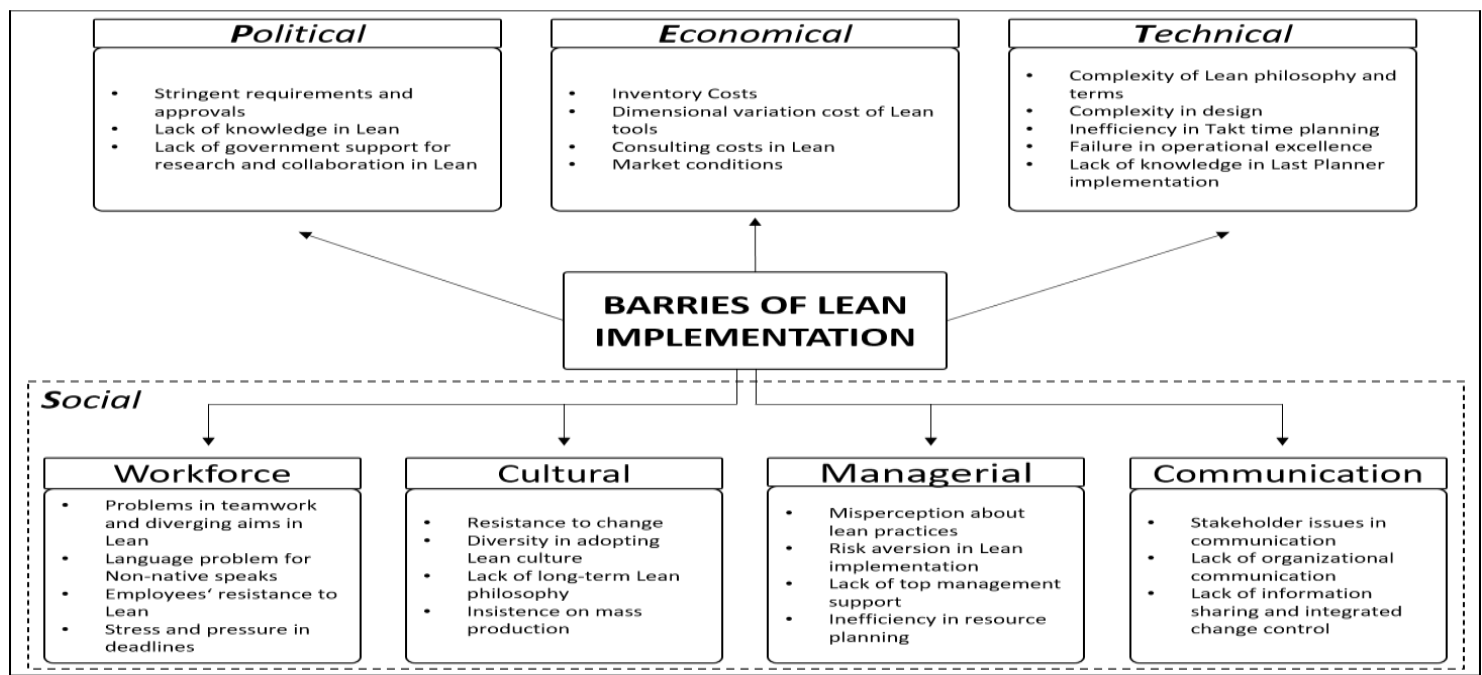

Figure 1. Barriers of Lean Implementation

Lack of government support for research and collaboration in Lean: Limited funding opportunities for research and collaboration in Lean practices lead to a narrower spectrum of Lean activities and scarcity of project specific applications of Lean (Shang and Pheng 2014).

\section{Economical Barriers}

Inventory costs: Inventory costs refer to the cost of storing the inventory. Often the inventory is calculated based on predictions and compensates uncertainties. The bullwhip effect even increases inventories. High inventories lead to slower processes in Lean implementation negating Lean activities (Kumar 2013, Jadhav et al. 2014, Almanei et al. 2017). Pulling (according to the Lean philosophy) the materials and information to the next work step allows the reduction of the inventory but requires a higher flexibility in the whole value chain.

Dimensional variation cost of Lean tools: Some Lean tools and methods lead to design variations resulting in extra cost. This might trigger the reluctance in implementing Lean tools (Kumar 2013, Jadhav et al. 2014).

Consulting costs in Lean: Consulting costs sometimes appear as financial burden for Lean implementation in construction projects, especially in smaller construction projects. This might lead to lower efficiency in implementation processes (Sarhan and Fox 2013, Ogunbiyi 2014).

Market conditions: Lean implementation brings the need to clarify objectives in terms of successful project execution and thus a stable construction process is sought. However, fluctuations in market conditions demand a constant flexibility of all involved companies. A communication structure supporting stability as well as flexibility in all processes is difficult to set up for companies implementing Lean construction the first time. This has potential to negate firms' willingness towards applying Lean practices and achieving excellence in their projects (Aziz and Hafez 2013, Sarhan and Fox 2013, Jadhav et al. 2014, Okere 2017). 


\section{Workforce Barriers}

Problems in teamwork and diverging aims in Lean: Lack of coordination and collaboration among team members might be observed when there are diverging aims within the firm. This results in inefficient processes in Lean practices (Aziz and Hafez 2013, Sarhan and Fox 2013, Shang and Pheng 2014, Jadhav et al. 2014).

Language problem for non-native speakers: Language is a barrier for most of the construction workers. This makes e.g. some safety tips difficult to understand and results in lower safety performance (Demirkesen and Arditi 2015). Educating construction workers about language barriers and providing some tips might lead to enhanced Lean performance. Thus, firms might develop ways to integrate non-native speakers in Lean processes to overcome this barrier (Jadhav et al. 2014).

Employees' resistance to Lean: Employees might resist to changes and this leads to inefficient performance in Lean practices. Some lean tools such as poka yoke devices or Kanban cards might be of interest to employees for the fact that they are not beware of benefits of using these tools. Thus, resistance to change is a major barrier for firms aiming to enhance Lean implementation performance (Aziz and Hafez 2013, Jadhav et al. 2014).

Stress and pressure in deadlines: Struggling with deadlines might create stress and pressure for construction workers. This might lead to wrong or missing practices in Lean (Aziz and Hafez 2013, Sarhan and Fox 2013, Howell et al. 2017).

\section{Cultural Barriers}

Resistance to change: Lean is a relatively new concept in the construction industry and this makes Lean adoption lower than expected by the industry practitioners. This also leads to lack of knowledge about the benefits of using Lean practices. Therefore, employees develop resistance to change for the fact that they are either unfamiliar with the Lean tools or its benefits. A company and project culture that is open for changes is required in order to lead all employees in the Lean transformation process. The resistance to change stems generally from the cultural background and is therefore listed as a major cultural barrier (Kumar 2013, Sarhan and Fox 2013, Jadhav et al. 2014, Ogunbiyi 2014, Shang and Pheng 2014, Almanei 2017).

Diversity in adopting Lean culture: Diversity in cultural background generally leads to different learning curves for differing groups. This leads to different levels of knowledge about Lean practices. Some construction workers have a hard time to adopt a Lean culture due to their diverse backgrounds and therefore they prefer to apply the conventional working practices they are familiar with. Therefore, diversity might appear as a cultural barrier for Lean implementation (Jadhav et al. 2014, Almanei et al. 2017).

Lack of long-term Lean philosophy: The adoption of the Lean philosophy is difficult for industry practitioners due to the dynamic nature of the construction industry. Industry practitioners mistrust the benefits that they will get by the use of Lean tools and this makes Lean implementation rare due to challenges with time and budget (Ogunbiyi 2014, Shang and Pheng 2014). 
Insistence on mass production: Mass production is affected by its repetitiveness. Here, nearly automatically, a "Lean" structure is built in the project-planning phase and a Lean implementation seems obvious (Demirkesen and Tommelein 2016). In contrast most of the construction projects are unique and complex. Therefore, the rules of mass production cannot be applied easily. This reluctance towards Lean implementation is embedded in a firm's culture.

\section{Managerial Barriers}

Misperception about Lean practices: There is a common perception that Lean practices are costly to apply. This makes firms reluctant towards adopting the Lean way considering that the practices also require special expertise (Jadhav et al. 2014, Almanei et al. 2017).

Risk aversion in Lean implementation: Firms might have concerns in terms of investing in Lean applications, which might be in a transparent and pre-aligned form due to uncertainties in construction projects. This might stem from the fact that benefits of Lean are not well understood by the majority of firms (Sarhan and Fox 2013, Shang and Pheng 2014, Jadhav et al. 2014, Almanei et al. 2017).

Lack of top management support: Top management's support for Lean practices is of utmost importance in terms of successful application of Lean in construction projects. When top management is reluctant towards adopting Lean thinking, some deficiencies might arise in Lean implementation (Kumar 2013, Sarhan and Fox 2013, Ogunbiyi 2014, Shang and Pheng 2014, Jadhav et al. 2014, Almanei et al. 2017, Okere 2017).

Inefficiency in resource planning: Inefficient planning of resources has the potential to generate waste and negatively impact Lean practices. Therefore, resource planning takes an important part in the successful management of Lean activities. When managed inefficiently, resource planning acts as a barrier for Lean implementation from a managerial perspective (Jadhav et al. 2014, Demirkesen and Tommelein, 2016).

\section{Communication Barriers}

Stakeholder issues in communication: Stakeholder engagement is crucial for the success of construction projects. Failure to engage stakeholders in project processes might lead to ineffective communication resulting in lower Lean performance (Sarhan and Fox 2013, Jadhav et al. 2014, Shang and Pheng 2014, Okere 2017).

Lack of organizational communication: Organizational communication is an effective way to circulate Lean concepts and terms. Lack of organizational communication leads to lower performance in Lean implementation (Salem et al. 2005, Kumar 2013, Jadhav et al. 2014, Ogunbiyi 2014, Howell et al. 2017, Okere 2017).

Lack of information sharing and integrated change control: Managing uncertainties and changes in the project are only possible with effective communication channels and lack of information sharing can break the Lean learning chain resulting in defective processes (Okere 2017, Howell et al. 2017).

\section{Technical Barriers}

Complexity of Lean philosophy and terms: There is still lack of understanding in Lean construction terms and philosophy. A common understanding of concepts to better practice 
Lean and perform more effectively in construction projects is needed. Hence, firms might need to remove this barrier in order to experience higher rates of performance in Lean projects (Salem et al. 2005, Kumar 2013, Sarhan and Fox 2013, Shang and Pheng 2014, Jadhav et al. 2014, Ogunbiyi 2014).

Complexity in design: Designing for Lean and safe operations is more challenging than traditional methods and this might lead to complexity in design, which makes design a barrier for Lean projects (Aziz and Hafez 2013, Sarhan and Fox 2013). Nevertheless, it has to be considered, that higher effort in design due to Lean practices results into stable working processes on site since design and processes are accordingly aligned from the beginning.

Inefficiency in Takt time planning: Multiple stakeholders and numerous interfaces might lead to poor planning in terms of Takt time. This negates Lean activities for the project and appears as a barrier for construction operations (Sundar et al. 2014).

Failure in operational excellence: Operational excellence is one of the objectives of Lean practices. Failure in operational excellence is likely to yield deficiencies in Lean processes. Therefore, it is considered as a technical barrier that firms need to address to better perform in Lean implementation (Salem et al. 2005, Sarhan and Fox 2013).

Lack of knowledge in Last Planner implementation: Last planner is a critical tool of Lean construction and failure to apply Last planner leads to unsuccessful operations in Lean implementation. Thus, it is listed as one of the technical barriers that firms need to consider aiming to achieve higher performance in Lean implementation (Aziz and Hafez 2013, Salem et al. 2005).

\section{SURVEY FINDINGS AND DISCUSSION}

As stated above a survey was conducted to understand the relevance of the barriers to Lean Implementation in construction. The survey was administered to large-scale engineering, construction and architectural firms in the U.S. The respondents were requested to rank Lean implementation barriers using a 1-5 point Likert scale $(1=$ very low, $2=$ low, $3=$ medium, $4=$ high and $5=$ very high). The survey was sent out to 205 corporate members of the LCI. A total of 72 out of 205 surveys were returned, representing a response rate of $35 \%$. To increase the response rate, some of the respondents were either called or invited for online meetings for the further explanation of the survey content. The response rate must have been a little higher but some of the e-mail addresses or contact information of respondents were either outdated or incorrect reducing the sample size less than 205. There are also research studies conducted with lower response rate but with valid justifications (Habermann et al. 2015). Hence, 35\% response rate is considered as a valid rate for evaluating survey data.

Table 1 presents the respondent profile. According to Table 1, it is shown that average years of experience of the companies in the construction industry is 42 years, whereas average years of experience in Lean implementation is 13, and the average number of employees of the respondents is 282 . 
Table 1. Respondent Profile

\begin{tabular}{lcccc}
\hline & Average & Median & Maximum & Minimum \\
Years of Experience in the Construction & 42 & 48 & 125 & 12 \\
Industry & 13 & 17 & 20 & 3 \\
Years of experience in Lean implementation & 282 & 38 & 10000 & 2 \\
Number of Employees &
\end{tabular}

Table 2 presents the results for the ranking of barriers for Lean implementation by Lean practitioners. According to Table 2, it is shown that "Lack of top management support" was rated as the top barrier (mean: 4.61). Secondly, "Misperception about Lean practices" and "Lack of information sharing and integrated change control" were rated as the following top barriers with average ratings of "4.14" and "4.09", respectively. "Lack of government support for research and collaboration in Lean" (mean: 3.04) and "Language problem for non-native speakers" (mean: 3.30) were rated as moderately important in terms of affecting Lean implementation.

Table 2. Ranking of Barriers for Lean Implementation

\begin{tabular}{ccc}
\hline Barrier & Mean & Rank \\
\hline Lack of top management support & 4.61 & 1 \\
Misperception about Lean practices & 4.14 & 2 \\
Lack of information sharing and integrated change control & 4.09 & 3 \\
Stakeholder issues in communication & 4.04 & 4 \\
Inefficiency in resource planning & 4.00 & 5 \\
Failure in operational excellence & 4.00 & 6 \\
\hline Barrier & Mean & Rank \\
\hline Lack of organizational communication & 4.00 & 7 \\
Employees' resistance to Lean & 3.96 & 8 \\
Resistance to change & 3.96 & 9 \\
Problems in teamwork and diverging aims in Lean & 3.91 & 10 \\
Diversity in adopting Lean culture & 3.91 & 11 \\
Lack of knowledge in Lean & 3.83 & 12 \\
Inventory costs & 3.74 & 13 \\
Lack of long-term Lean philosophy & 3.67 & 14 \\
Market conditions & 3.65 & 15 \\
Stress and pressure in deadlines & 3.65 & 16 \\
Complexity of Lean philosophy and terms & 3.64 & 17 \\
Risk aversion in Lean implementation & 3.61 & 18 \\
Complexity in design & 3.57 & 19
\end{tabular}




\begin{tabular}{ccc} 
Inefficiency in Takt time planning & 3.57 & 20 \\
Stringent requirement and approvals & 3.57 & 21 \\
Dimensional variation cost of Lean tools & 3.52 & 22 \\
Lack of knowledge in Last Planner implementation & 3.52 & 23 \\
Insistence on mass production & 3.52 & 24 \\
Consulting costs in Lean & 3.43 & 25 \\
Language problem for non-native speakers & 3.30 & 26 \\
Lack of government support for research and collaboration in Lean & 3.04 & 27 \\
\hline
\end{tabular}

As survey findings indicated lack of top management was previously listed as a major barrier by several researchers (Jadhav et al. 2014, Almanei et al. 2017, Okere 2017). This proves the importance of top management support in conducting an efficient Lean implementation program. When top management is involved in the processes of Lean, implementation becomes smoother and more transparent leading to higher efficiency in processes. The survey findings also implied that misperception about Lean practices is a major barrier for construction firms in implementing Lean. This proves that the benefits of implementing Lean has not yet well understood by the majority of construction professionals. This might stem from the fact that Lean implementation is thought to be costly and require special expertise for practicing efficiently (Jadhav et al. 2014, Almanei et al. 2017). Lack of information sharing and control was also listed among top barriers of Lean implementation by the survey respondents. This finding is in line with the statement that uncertainties and changes in the project might be handled with effective communication channels and lack of information sharing might lead to defective processes in Lean implementation (Howell et al. 2017).

\section{CONCLUSION}

Lean implementation is a relatively new practice in the construction industry. Therefore, certain concerns emerge for those, who aim to implement Lean in their projects. This study focuses on determining the barriers hindering a successful Lean implementation. In this respect, an in-depth literature review was assessed to reveal the barriers of Lean implementation in the construction industry. Then, an online questionnaire was sent out to members of the LCI for ranking the barriers based on a Likert scale. The questionnaire results indicated that most important barriers can be found in the socio-cultural background. The top three listed barriers are: 'Lack of top management support', 'misperception about Lean practices', 'lack of information sharing and integrated change control'. The study is expected to provide a roadmap for construction practitioners to best practice Lean concepts.

\section{ACKNOWLEDGMENTS}

The authors would like to thank the members of Lean Construction Institute (LCI), who took time responding the online questionnaire. 


\section{REFERENCES}

Almanei, M., Salonitis, K., and Xu, Y. (2017). "Lean implementation frameworks: the challenges for SMEs." Procedia CIRP, 63, 750-755.

Ayarkwa, J., Agyekum, K., Adinyira, E., and Osei-Asibey, D. (2012). "Barriers to successful implementation of lean construction in the ghanaian building industry." Journal of Construction < http://dspace.knust.edu.gh/bitstream/123456789/10837/1/ BARRIERS\%20TO\%20SUCCESSFUL\%20IMPLEMENTATION\%20OF\%20LEAN \%20CONST..pdf > (Jan 14, 2019).

Aziz, R.F., Hafez, S.M. (2013). "Applying lean thinking in construction and performance improvement," Alexandria Engineering Journal, 52(4), 679-695.

Ballard, G., Howell, G. (2004). "Competing Construction Paradigms." Lean Construction Journal, 1(1), 38-45.

Demirkesen, S., and Arditi, D. (2015). "Construction safety personnel's perceptions of safety training practices." International Journal of Project Management, 33(5), 11601169.

Demirkesen, S., and Tommelein, I. D. (2016). "Lean Management Methods for Design and Construction : Built-in-Quality and Safety-by-Design”, In Proceedings of Advances in Civil Engineering Conference (ACE2016), Istanbul, Turkey.

Devaki, M. P., and Jayanthi, R. (2014). "Barriers to implementation of lean principles in the Indian construction industry." International Journal of Engineering Research \& Technology, 3(5), 1189-1192.

Habermann, M., Blackhurst, J., and Metcalf, A. Y. (2015). "Keep your friends close? Supply chain design and disruption risk. ” Decision Sciences, 46(3), 491-526.

Howell G., Ballard G., and Demirkesen S. (2017). "Why Lean Projects Are Safer", In LC3 2017: Proceedings of the 25 $5^{\text {th }}$ Annual Conference of the International Group for Lean Construction (IGLC), Crete, Greece.

Jadhav, J., Mantha, S., and Rane, S. (2014). "Exploring barriers in lean implementation." International Journal of Lean Six Sigma, 5(2), 122-148.

Koskela, L. (1992). "Application of the new production philosophy to construction", Technical report No. 72, Centre for Integrated Facility Engineering, Stanford University, CA.

Krafcik, J. F. (1988). "Triumph of the lean production system.” MIT Sloan Management Review, 30(1), 41.

Kumar S. (2013). "Enablers of Lean Six Sigma Implementation in Business Environment: A Review" In Proceedings of International Conference on Smart Technologies for Mechanical Engineering, 409-417, Delhi Technological University, New Delhi, India.

Lean Construction Institute (LCI) (2004). "What is Lean Construction?." <http://www.leanuk.leanconstruction.org/whatis.htm> (Feb 24, 2018).

Liker, J. K., and Convis, G. L. (2012). The Toyota way to lean leadership. McGraw-Hill, New York.

Meadows, D. (2011). “Designing out Waste." Environmental Design and Construction Magazine, <http://www.modular.org/marketing/documents/DesigningoutWaste_ EDC.pdf> (June 3, 2017). 
Mossman, A. (2009). "Why Isn't the UK Construction Industry Going Lean with Gusto?." Lean Construction Journal, 5(1) 24-36.

Ogunbiyi, O. (2014). "Implementation of the Lean Approach in Sustainable Construction : A Conceptual Framework", PhD Diss., University of Cental Lancashire, Lancashire, UK.

Okere, G. O. (2017). "Barriers and enablers of effective knowledge management: A case in the construction sector." Electronic Journal of Knowledge Management, 15(2), 85.

Porter, M. (1985). Competitive Advantage. The Free Press, New York, NY.

Salem, O., Solomon, J., Genaidy, A. and Minkarah, I. (2006). "Lean construction: from theory to implementation." Journal of Management in Engineering, 22(4), 168-175.

Sarhan S., and Fox, A.(2013). "Barriers to Implementing Lean Construction in the UK Construction Industry." Built Hum. Environ. Rev., 6, 1-17.

Steinmann, H., and Schreyögg, G. (2006). Management: Grundlagen der Unternehmensführung. 6th edition, Wiesbaden.

Sundar, R., Balaji, A. N., and Kumar, R. S. (2014). "A review on lean manufacturing implementation techniques." Procedia Engineering, 97, 1875-1885.

Wandahl, S. (2014). Lean construction with or without lean-challenges of implementing lean construction. In Proceedings of the 22nd Annual Conference of the International Group for Lean Construction (97-108). Oslo, Norway.

Womack, J. P., Womack, J. P., Jones, D. T., and Roos, D. (1990). Machine that changed the world. Simon and Schuster Inc., New York, NY.

Womack, J. P., and Jones, D. T. (1996). Lean Thinking: Banish Waste and Create Wealth in Your Corporation. Simon \& Schuster Inc., New York, NY. 